\title{
A Study on Characterization of EPS and Media Optimization for Bacterial Calcium Carbonate Precipitation
}

\author{
J. Neena Priya ${ }^{1,2}$, M. Kannan ${ }^{3}$, P.Priyanka ${ }^{1}$ and S. Vergin Mary ${ }^{1}$ \\ ${ }^{1}$ Research \& Development Centre, Bharathiar University, Coimbatore- 641 046, India \\ ${ }^{2}$ Department of Microbiology, Dr. MGR Janaki College of Arts and Science for Women, \\ Chennai- 600 028, India \\ ${ }^{3}$ Department of Microbiology, V. H. N. S. N. College, Virudhu nagar 626 001, India \\ *Corresponding author
}

A B S T R A C T

Keywords

Calcium

carbonate,

EPS,

Biomineralization,

Optimization.

Article Info

Accepted:

20 March 2016

Available Online:

10 April 2016
Bacteria isolated from different habitats have been reported for their ability to precipitate calcium carbonate both in natural and laboratory conditions. Calcium carbonate precipitation was a known example of extracellular bacterial biomineralization and this process played an important role in calcium precipitation. In this study bacterium such as Bacillus $s p$ and Pseudomonas sp precipitated calcium carbonate in an in vitro condition. Optimization of the medium was carried out and the extracellular polymeric substance that influenced the process of precipitation was extracted by both physical and chemical methods and its chemical analysis of carbohydrate and protein content was performed. The extracellular polymeric substance by these bacteria mediated calcium carbonate precipitation and thereby has new revolution in various applications.

\section{Introduction}

Biomineralization refers to the processes by which organisms' forms minerals. These minerals are composite materials comprised of both mineral and organic components. The organism uses cellular activities to direct the nucleation, growth, morphology and final location of the mineral that is deposited both intra and extracellularly (Weiner et al., 2003). Number of studies has investigated the role of extracellular polymeric substances on mineral precipitation and showed that it significantly alters the surface environment of bacterial cells, as well as providing an additional source of organic ligands and dissolved organic carbon. It alters the kinetic pathways of mineral nucleation and crystal growth. EPS is very common in natural environments, a major component of biofilms, makes it stable and protect it from harmful effects, as well as reducing water 
loss from the cell to environment (Tourney et al., 2009). EPS is composed of high molecular weight compounds, including polysaccharide, protein, nucleic acids, humic substances and ionisable functional groups like carboxylic, phosphoric, amino and hydroxyl groups. EPS has a large number of negatively-charged functional groups and form multiple complexes with many heavy metal ions and remove them.

Bacteria of the genus Bacillus are ubiquitous organisms found in the soil and are able to precipitate calcite on their cell constituents and in their micro environment. Pseudomonas sp also has ability to precipitate calcite crystals. Researchers have used standard nutrient media like nutrient agar medium or yeast extract medium to grow bacteria and precipitated calcium carbonate (V. Achal et al., 2009). In this study, strains of both bacteria such as Bacillus sp and Pseudomonas sp which have precipitated calcium carbonate was selected for further investigation of media optimization with different carbon and nitrogen sources and extraction of EPS by both physical and chemical methods and characterize the composition of EPS and its influence in calcium carbonate precipitation. The applications of bacterially produced carbonate biominerals are improvement of the durability of buildings, remediation of environment (water and soil), sequestration of atmospheric $\mathrm{CO}_{2}$, filler material in rubbers and plastics.

\section{Materials and Methods}

\section{Screening of Calcium Carbonate Precipitating Isolates}

Bacteria were isolated from soil of rhizosphere and biochemical identification tests were performed and identified. The obtained isolates were screened for calcium carbonate precipitation. Calcite, the stable crystal modification of calcium carbonate, grows from hard water in clusters, which after a certain time form a solid scale firmly attached to the surface where the nucleation of crystals started. The presence of calcite was demonstrated on the special medium by inoculating into Triplicate B4 medium (calcium acetate $2.5 \mathrm{~g}$, Yeast extract $4 \mathrm{~g}$, Glucose 10g, Agar 18g/1000ml of distilled water, $\mathrm{pH} 7.2$ ) incubated at $37^{\circ} \mathrm{C}$ for 28 days and the precipitates was purified by filtration, washed with sterile distilled water and dried at $60^{\circ} \mathrm{C}$ overnight (Chiara et al., 2006).

\section{Optimization of Calcium Carbonate Precipitation Medium}

The medium that precipitates calcium carbonate was optimized by evaluating the effect of the precipitates with change in the carbon and nitrogen sources. The media components of the B4 medium were optimized by changing one parameter while remaining parameters to be kept unaltered. The carbon source was optimized by changing dextrose to glucose, sucrose and lactose. Similarly nitrogen source was optimized by changing yeast extract to beef extract and peptone. The isolates were inoculated and incubated at $37^{\circ} \mathrm{C}$ for $24 \mathrm{hrs}$, $48 \mathrm{hrs}$ and $72 \mathrm{hrs}$ and the growth of the organism that mediates calcium carbonate precipitation was monitored by obtaining the optical density (Jinlong Zhang et al., 2014).

\section{Extraction of EPS}

The cell suspension of both the isolates was further subjected to EPS extraction by different methods. The physical method used for extraction of EPS was high speed centrifugation where the cell suspension was centrifuged at $20000 \mathrm{r} / \mathrm{min}$ at $4^{\circ} \mathrm{C}$ for 20 min. The supernatant was filtered. The chemical method used three extractants, EDTA $2 \%$ at $4^{\circ} \mathrm{C}$ for $3 \mathrm{hrs}$, formaldehyde at 
$4^{\circ} \mathrm{C}$ for $1 \mathrm{hr}$ and formaldehyde plus $\mathrm{NaOH}$ $(1 \mathrm{~N})$ at $4^{\circ} \mathrm{C}$ for $3 \mathrm{hrs}$. After all the isolated treated with chemical agents was subjected to centrifugation at $20000 \mathrm{r} / \mathrm{min}$ at $4^{\circ} \mathrm{C}$ for $20 \mathrm{~min}$ and the supernatants were filtered. The filtrate was obtained by both the methods and was further used for characterization studies (Xiangliang Pan et al., 2009).

\section{Chemical Analysis of EPS}

The chemical analysis of EPS obtained by both physical and chemical methods of extraction for both the isolates was assessed. The carbohydrate content of EPS was determined by the Phenol sulphuric acid assay with glucose solution as standard. (Dubois et al., 1956). The protein content of EPS was determined by Lowry's method with bovine serum albumin as standard (Hong Liu et al., 2002).

\section{Results and Discussion}

The isolates obtained after preliminary and biochemical identification tests were confirmed as Bacillus sp and Pseudomonas $s p$ respectively. These bacteria were known for its ability to precipitate calcium carbonate in the B4 medium, which was confirmed by previous studies. The B4 medium was optimized by varying carbon and nitrogen sources. Among the carbon sources, glucose and lactose (Figure: $1 \& 3$ ) showed high growth rate than sucrose for both Bacillus sp and Pseudomonas sp. Among the nitrogen sources, beef extract and peptone (Figure: $2 \& 4$ ) showed high growth rate than yeast extract for both Bacillus sp and Pseudomonas sp.

EPS was extracted from both Bacillus sp and Pseudomonas sp by both physical and chemical method was further analysed for its carbohydrate and protein content. The maximum protein content was $9.5 \mathrm{mg} / \mathrm{g}$ of Bacillus sp and $7.7 \mathrm{mg} / \mathrm{g}$ of Pseudomonas sp by the chemical method extraction using EDTA (Figure: 5). The least protein content was obtained by the physical method of extraction. The maximum carbohydrate content was obtained by the chemical method of extraction using EDTA for both the organisms (Figure: 6).

The calcium precipitating activity of bacteria is the key factor of self-healing effectiveness of concrete crack. Marine bacteria with high calcium precipitating bacteria was screened and identified. The effects of influential factors such as carbon source, nitrogen source, spore inoculum and $\mathrm{pH}$ on the performances of bacterially induced calcium carbonate precipitation were investigated. This study laid a foundation for further application of bacterial self-healing of concrete crack (Jinlong Zhang et al., 2014).

Figure.1 Optimization of Carbon Source - Bacillus sp

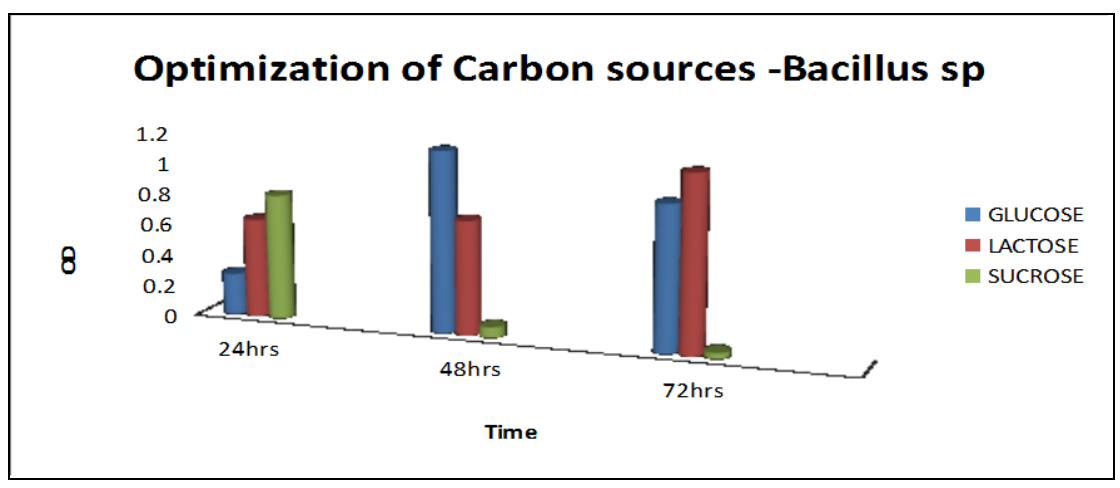


Figure.2 Optimization of Nitrogen Sources - Bacillus $S p$

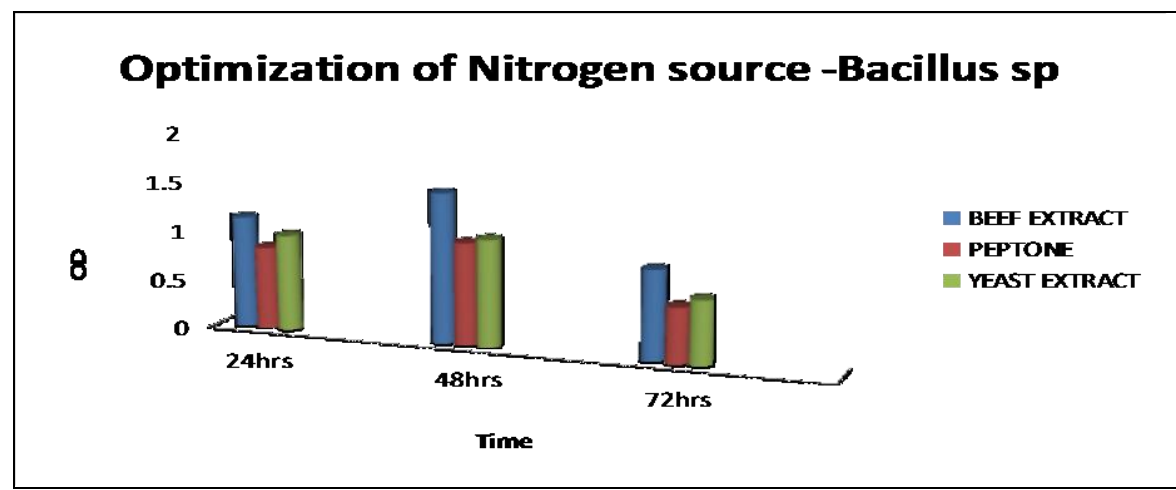

Figure.3 Optimization of Carbon Sources - Pseudomonas $S p$

\section{Optimization of Carbon sources -Pseudomonas sp}

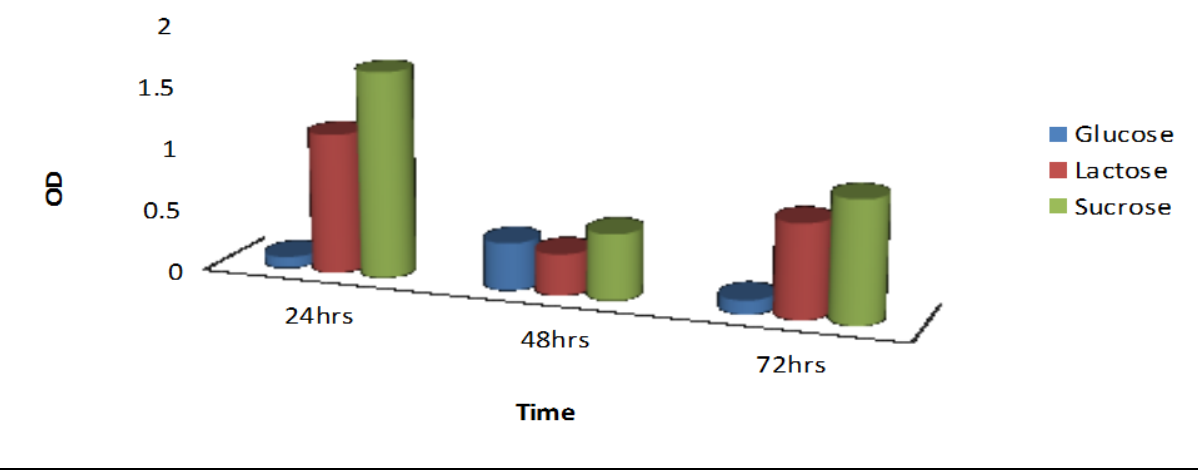

Figure.4 Optimization of Nitrogen Sources - Pseudomonas Sp

\section{Optimization of Nitrogen sources -Pseudomonas sp}

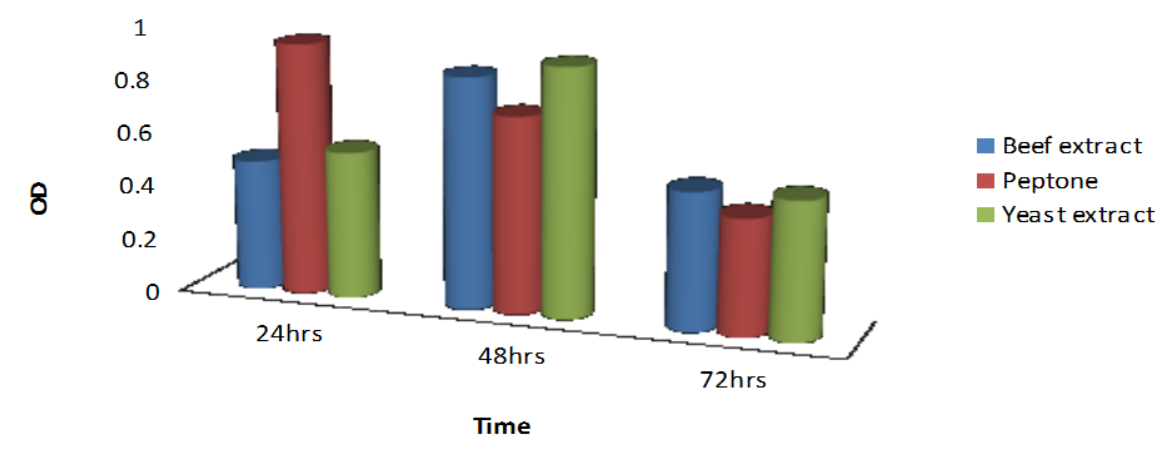


Figure.5 Chemical Analysis of EPS - Protein Content

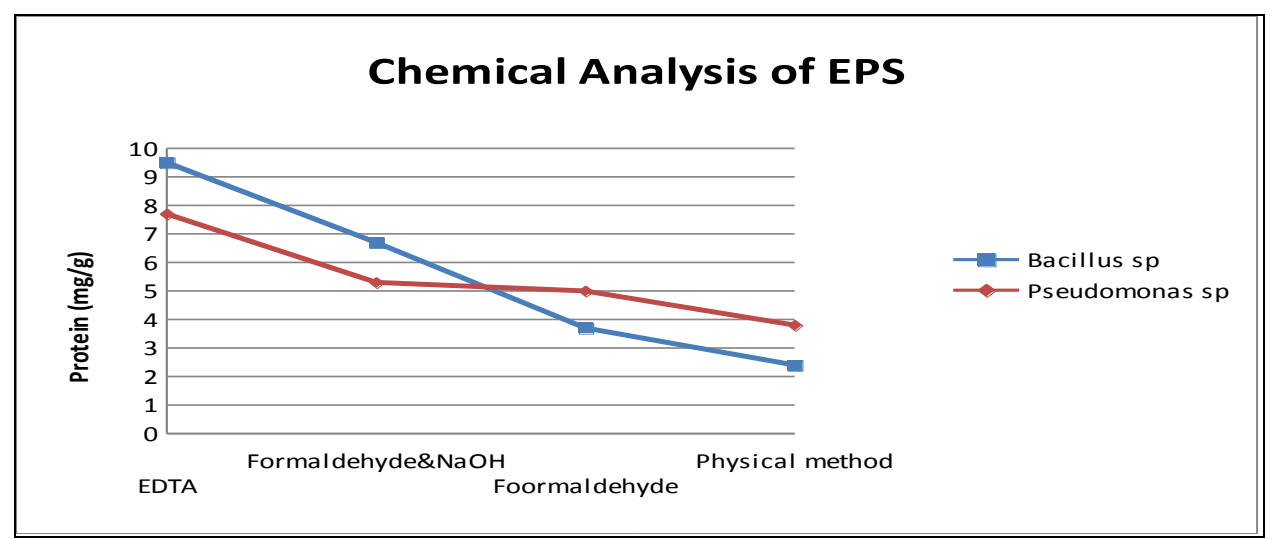

Figure.6 Chemical Analysis of EPS - Carbohydrate Content

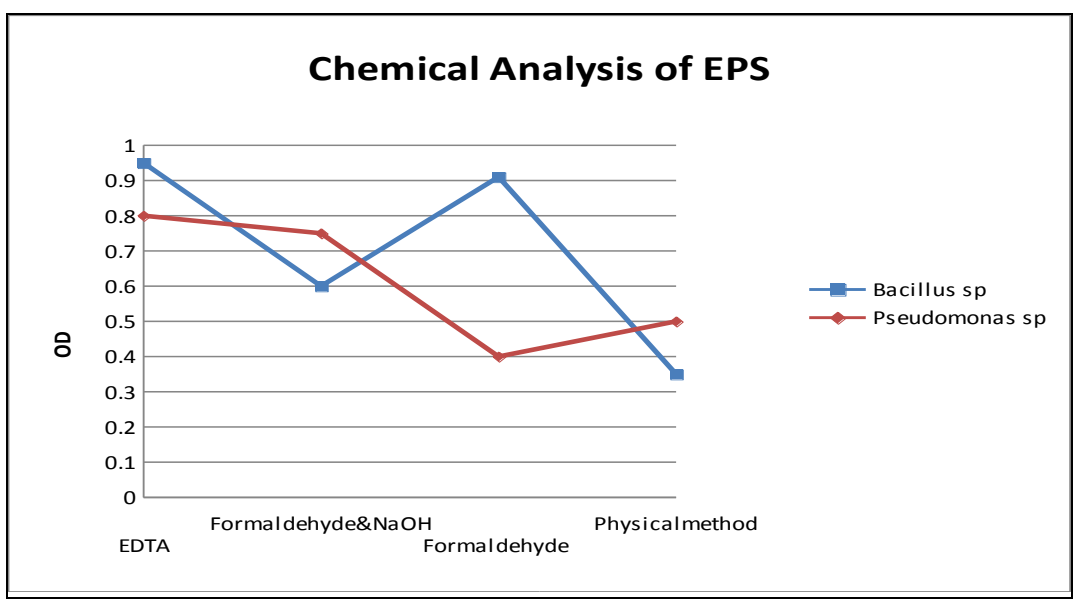

Modified B4 showed a greater decrease in calcium ions than 295 , for all strains tested, indicating that more calcium carbonate was produced in the former medium. Modified B4 gave greater calcium carbonate precipitation. In modified B4, Pseudomonas putida consumed on average $96 \%$ and Bacillus subtilis $28 \%$ calcium ion compared to the negative control without bacteria (Marcia et al., 2011). The carbon and nitrogen sources used in the present study showed significant effect on the precipitation of calcium carbonate especially glucose and lactose among the carbon sources and beef extract and peptone among the nitrogen sources for both the organisms.
EPS had been extensively studied with regard to its physiochemical properties, interactions with contaminants and role in biofilm formation. The yield of EPS from biofilm varied greatly with the extraction methods. Compared with the physical methods, chemical methods significantly increased the extraction yield. The protein content of EPS obtained a yield of $1.70 \mathrm{mg} / \mathrm{g}$ by EDTA method, $8 \mathrm{mg} / \mathrm{g}$ by Formaldehyde method and $17.07 \mathrm{mg} / \mathrm{g}$ by Formaldehyde$\mathrm{NaOH}$ method (Xiangliang Pan et al., 2010). The EPS extracted in the present study showed maximum yield of $9.5 \mathrm{mg} / \mathrm{g}$ by Bacillus $s p$ and $7.7 \mathrm{mg} / \mathrm{g}$ by Pseudomonas $s p$ by the chemical method, especially EDTA 
extraction than the other chemical and physical method.

Biomineralization usually involves metabolic activities of microorganisms and can occur in a biologically controlled, biologically influenced or biologically induced manner. Utilization of this natural process could be a turning point in the field of environmental engineering. Microbially induced biominerals by microorganisms are being extensively used in various fields ranging from removal of heavy metals and radio nucleotides to remediation of building materials. The present paper stands as significant demonstration on optimization and analysis of EPS by bacteria especially Bacillus sp and Pseudomonas sp that ultimately mediates calcium carbonate precipitation.

\section{References}

Achal, V., Mukherjee, A., Basu, P.C., Reddy, M.S., 2009. Lactose mother liquor as an alternative nutrient source for microbial concrete production by Sporosarcina pasteurii, J. Ind Microbiol Biotechnol. 36:433-438.

Chiara Barabesi, Alessandro Galizzi., Giorgio Mastromei., Mila Rossi., Elena Tamburini., Brunella Perito. 2006. Bacillus subtilis Gene Cluster Involved in Calcium Carbonate Biomineralization. Journal of bacteriology. 189: 228-351

Dubois M., Gilles K.A., Hamilton J.K., Rebers P.A., Smith, F 1956.

\section{How to cite this article:}

Neena Priya, J., M. Kannan, P.Priyanka and Vergin Mary, S. 2016. A Study on Characterization of EPS and Media Optimization for Bacterial Calcium Carbonate Precipitation Int.J.Curr.Microbiol.App.Sci. 5(4): 590-595. doi: http://dx.doi.org/10.20546/ijcmas.2016.504.067
Calorimetric method for determination of sugars and related substances. Anal.Chem. 28(3): 350356

Janette Tourney, Bryne T. Ngwenya. 2009. Bacterial extracellular polymeric substances (EPS) mediate $\mathrm{CaCO}_{3}$ morphology and polymorphism. Chemical geology 262: 138-146.

Jinlong Zhang., Jinlong Ke., Bing Liu., Xu Deng., Ningxu Han., Feng Xing., 2014. China.

Hong Liu., Herbert H.P. Fang. 2002. Extraction of extracellular polymeric substances (EPS) of sludges. Journal of Biotechnology 95: 249-256

Márcia Aiko Shirakawa., Maria Alba Cincotto., Daniel Atencio., Christine C.Gaylarde., Vanderley M. John. 2011. Effect of culture medium on biocalcification by pseudomonas putida, lysinibacillus sphaericus and Bacillus subtilis. Brazilian Journal of Microbiology 42: 499-507.

Steve Weiner. Patricia M. Dove. 2003. An Overview of Biomineralization Processes and the problem of the vital effect.

Xiangliang Pan., Jing Liu., Daoyong Zhang., Xi Chen., Lanhai Li., Wenjuan Song., Jianying Yang. 2009. A comparision of five extraction methods for extracellular polymeric substances (EPS) from biofilm by using three dimensional excitation- emission matrix (3DEEM) fluorescence spectroscopy. 111-116. 